\title{
Effect of nanocellulose polymorphism on electrochemical analytical performance in hybrid nanocomposites with non-oxidized single-walled carbon nanotubes
}

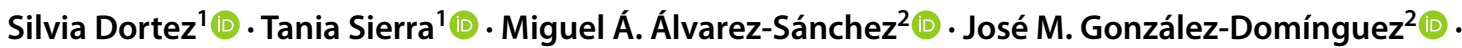

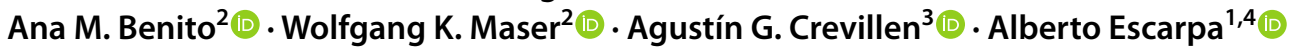

Received: 7 September 2021 / Accepted: 28 December 2021 / Published online: 14 January 2022

(c) The Author(s) 2022

\begin{abstract}
Two cellulose nanocrystals/single-walled carbon nanotube (CNC/SW) hybrids, using two cellulose polymorphs, were evaluated as electrochemical transducers: CNC type I (CNC-I/SW) and CNC type II (CNC-II/SW). They were synthesized and fully characterized, and their analytical performance as electrochemical sensors was carefully studied. In comparison with SWCNT-based and screen-printed carbon electrodes, CNC/SW sensors showed superior electroanalytical performance in terms of sensitivity and selectivity, not only in the detection of small metabolites (uric acid, dopamine, and tyrosine) but also in the detection of complex glycoproteins (alpha-1-acid glycoprotein (AGP)). More importantly, CNC-II/SW exhibited 20 times higher sensitivity than CNC-I/SW for AGP determination, yielding a LOD of $7 \mathrm{mg} \mathrm{L}^{-1}$. These results demonstrate the critical role played by nanocellulose polymorphism in the electrochemical performance of CNC/SW hybrid materials, opening new directions in the electrochemical sensing of these complex molecules. In general, these high-active-surface hybrids smartly exploited the preserved non-oxidized SW conductivity with the high aqueous dispersibility of the CNC, avoiding the use of organic solvents or the incorporation of toxic surfactants during their processing, making the $\mathrm{CNC} / \mathrm{SW}$ hybrids promising nanomaterials for electrochemical detection following greener approaches.
\end{abstract}

Keywords Single-walled carbon nanotube $\cdot$ Green chemistry $\cdot$ Cellulose nanocrystal $\cdot$ Sustainability $\cdot$ Electrochemical detection

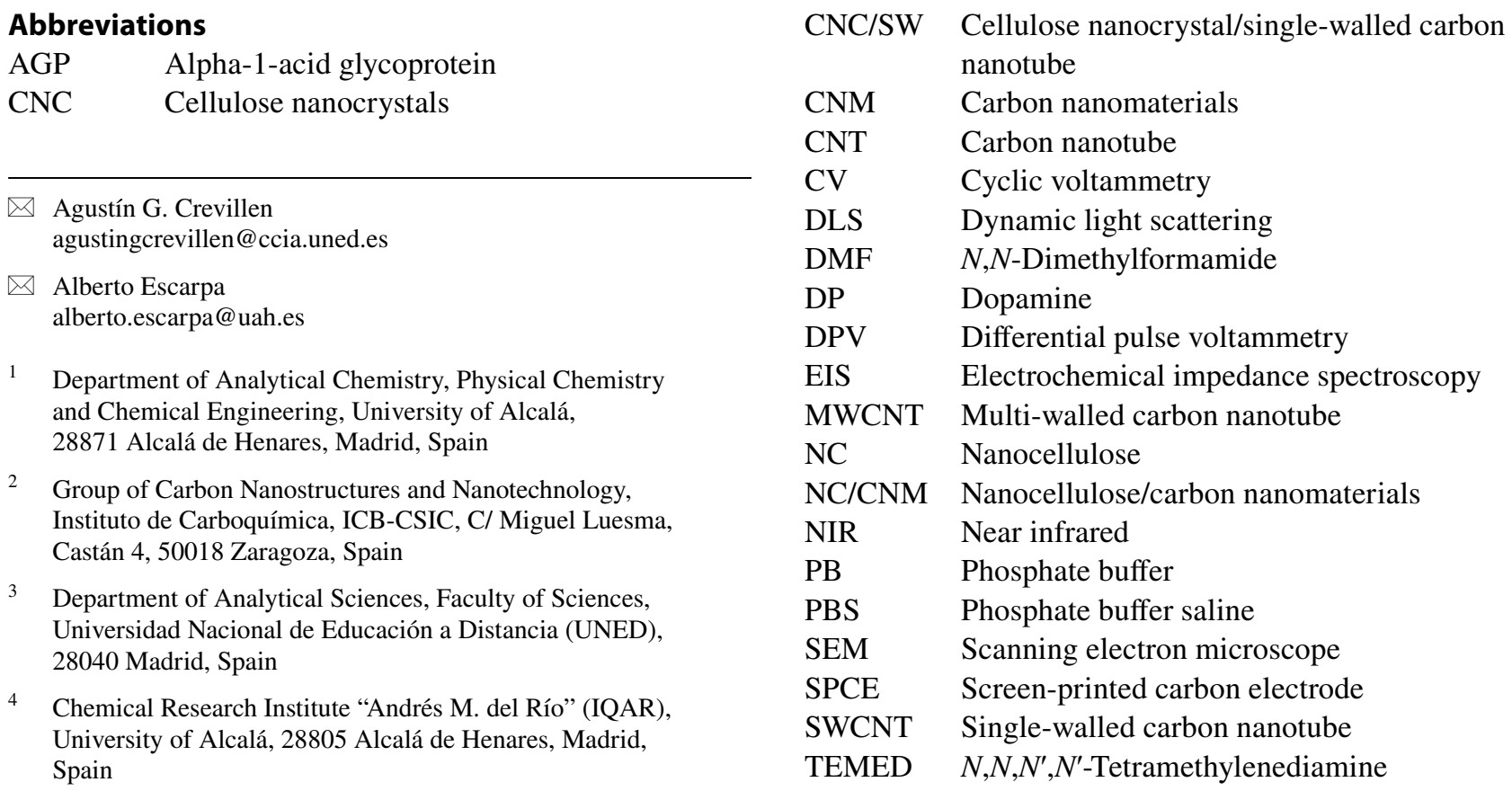




$\begin{array}{ll}\text { Tyr } & \text { Tyrosine } \\ \text { UA } & \text { Uric acid } \\ \text { XRD } & \text { X-ray diffraction }\end{array}$

\section{Introduction}

The need for sustainable alternatives to conventional materials has led to a growth in demand for bio-based materials directed to applications in different areas of the industry. Among them, nanocellulose (NC) has become a promising alternative in nanotechnology applications and the focus of intensive research, because of its attractive properties such as biocompatibility, biodegradability, renewable nature, nontoxicity, anisotropic shape, excellent mechanical properties, tailorable surface chemistry, and interesting optical properties [1-4].

Nanocellulose can be categorized into three types: (I) cellulose nanocrystals (CNC), also referred to as nanocrystalline cellulose; (II) cellulose nanofibrils, also referred to as nano-fibrillated cellulose; and (III) bacterial cellulose [1, 4]. Besides, CNC shows at least four main polymorphs, namely cellulose I, cellulose II, cellulose III, and cellulose IV, being I and II differentiated upon the different orientations of cellulose chains [5]. Cellulose I and II are the most studied and reported [6]. Briefly, type I is dominant in natural cellulose sources and exhibits a parallel arrangement of chains with sharp and straight needle-like morphology, while type II is obtained by dissolution and recrystallization of type I, displaying an antiparallel arrangement with shorter and twisted rod-like nanocrystals [5]. These differences between types I and II in their structures and morphologies provide them with different properties and behavior. For example, CNC type II is more enzymatically degradable than type I [7], and also, these nanostructures may exert very different properties to their hybrids with other nanostructures. As a matter of example, we recently demonstrated that dispersions of SWCNT with CNC type II exhibited selective cytotoxicity on human colon cancer (Caco-2) cells, with no harm on equivalent normal (healthy) cells, while the SWCNT hybrids with CNC type I were generally innocuous [6].

Taking advantage of the aforementioned features, $\mathrm{NC}$ has been extensively applied in drug delivery [8], environmental monitoring and remediation $[9,10]$, food safety $[11,12]$, and chemical/physical/mechanical sensing [13, 14]. Regarding electrochemical sensors, the interest in NC is recent. As NC is not conductive, a general strategy to circumvent this issue is to combine it with carbon nanomaterials (CNM, such as carbon nanotubes (CNT) or graphene derivatives) designing hybrid materials with high conductivity and enhanced mechanical strength [15-19]. The preference for this synergistic approach is because CNM and NC have high affinity for each other. Furthermore, the favorable interactions between CNM and NC prevent their natural tendency to selfaggregate [20]. As a matter of fact, some authors have identified such favorable interaction between CNT and CNC as the association of hydrophobic (200) planes of CNC with the (also very) hydrophobic $\mathrm{sp}^{2}$ carbon lattice of CNT, entailing the alignment of CNC along the tube axis in SWCNT [21].

Another advantage of these hybrids is that they are readily dispersed in water while pristine or poorly oxidized CNM are difficult to disperse in water and organic solvents [1]. This is very interesting in sensor fabrication because it allows preparing it without using organic solvents, approaching to the Green Chemistry concept [22, 23]. Moreover, these NC/CNM hybrids can be used to produce electrically conductive fabric for developing high-performance wearable sensors [24].

There are only a few examples in the literature about the use of NC/CNM hybrids for electrochemical sensing despite the potential advantages [15-19]. Shahrokhian's group reported a cellulose nanofiber/nanocarbon modified electrode for the detection of two drugs: clonazepam [19] and metoclopramide [18]. An increase in the electroactive surface area of sensors and in the analyte peak currents was demonstrated by using this hybrid material. However, the type and characteristics of the used nanocellulose were not reported. Shalauddin et al. developed a hybrid NC/functionalized MWCNT nanocomposite for the electrochemical sensing of diclofenac sodium in pharmaceutical drugs and biological fluids [15]. MWCNTs were functionalized with carboxylic groups by strong acid treatment. This hybrid nanocomposite showed lower electron transfer resistance and better sensitivity towards diclofenac than each nanomaterial separately. Ortolani et al. prepared a glassy carbon electrode modified by single-walled carbon nanohorns and $\mathrm{NC}$ for sensing of adenine and guanine [16]. This NC/single-walled carbon nanohorn hybrid provided a strong electrocatalytic response towards both analytes, increasing the sensor sensitivity. Finally, a silylated graphene oxide-grafted-chemically modified nanocellulose (Si-GO-g-CMNC) was fabricated for electrochemical sensing of cholesterol [17]. This new material was integrated in a molecular imprinting polymer sensor to carry out a selective detection of cholesterol.

However, in the last three references [15-17], the authors used the term "nanocellulose" in a generic way and did not mention or study the type of nanocellulose polymorph (I-IV) being employed. Nevertheless, according to X-ray diffraction (XRD) pattern reported in these articles, CNC were of type I that is the natural polymorph of cellulose. In fact, very scarce works in NC/CNM type II hybrids have been reported to date [6].

Regarding the different properties reported in the literature for CNC types I and II [7], and their respective CNM hybrids [6], it seems pertinent to study each nanocellulose polymorph (i.e., crystalline structure) in the electrochemical 
performance of NC/CNM hybrid sensors, because unique or novel responses and performances could arise. Additionally, the use of non-oxidized CNM is of relevance to preserve their conductive properties, but it is scarcely addressed, despite the excellent dispersive action of CNC towards nonoxidized CNTs in water [6, 21].

In consequence, we synthesized two different non-oxidized CNC/SW hybrids: one using CNC type I (CNC-I/SW) and another using CNC type II (CNC-II/SW). They were fully characterized, and their electrochemical performance was carefully studied and compared to bare SWCNTs and screen-printed carbon electrodes (SPCEs). Then, CNC/ $\mathrm{SW}$ hybrids were used as transducers in the development of electrochemical sensors for detecting target compounds with clinical interest (uric acid, dopamine, tyrosine, and alpha-1-acid glycoprotein) by differential pulse voltammetry (DPV). The aim of the present work is to shed light on the potential interest of CNC hybrids with CNM as regards electrochemical sensing technologies, and the relevance that the $\mathrm{CNC}$ polymorphism acquires in such scenario.

\section{Materials and methods}

\section{Reactive and materials}

$\mathrm{K}_{4} \mathrm{Fe}(\mathrm{CN})_{6} \cdot 3 \mathrm{H}_{2} \mathrm{O}, \mathrm{K}_{3} \mathrm{Fe}(\mathrm{CN})_{6}, \mathrm{Ru}\left(\mathrm{NH}_{3}\right)_{6} \mathrm{Cl}_{3}, N, N$-dimethylformamide (DMF), alpha-1-acid glycoprotein (AGP) $(\geq 99 \%)$, transferrin ( $\geq 98 \%$ ), human serum (certified reference material, ERM-DA470K/IFCC), potassium osmate (VI) dihydrate, $N, N, N^{\prime}, N^{\prime}$-tetramethylenediamine (TEMED), potassium nitrate ( $\geq 98 \%$ ), uric acid, dopamine, L-tyrosine, and cellulose microcrystalline powder $(20 \mu \mathrm{m})$ were purchased from Sigma-Aldrich (Darmstadt, Germany). Hydrochloric acid (37\%), sulfuric acid (95-98\%), sodium chloride, disodium hydrogen phosphate, and sodium dihydrogen phosphate were purchased from PanReac (Barcelona, Spain).

SWCNTs were acquired from Carbon Solutions Inc. (type P2-SWNT, Riverside, CA, USA). These correspond to a purified material following a non-specified non-oxidative process.

For the synthesis of $\mathrm{CNC}$ and characterization of $\mathrm{CNC} /$ SW hybrids, ultrapure water was obtained from a Siemens Ultraclear device, with a conductivity of $0.055 \mu \mathrm{S} \mathrm{cm}^{-1}$. For the analytical studies, all aqueous solutions were prepared in Milli-Q water (Merck Millipore, Darmstadt, Germany).

\section{Instrumentation}

A Shimadzu UV-2401PC spectrophotometer was used to determine the SWCNT concentration in both dispersed hybrids, which were diluted with ultrapure water to adjust the absorbance to $\sim 0.4$ at $850 \mathrm{~nm}$, using ultrapure water for blank measurements.

Near infrared (NIR) absorption spectroscopy was performed in the liquid phase using a Bruker VERTEX 70 spectrometer and $2 \mathrm{~mL}$ polystyrene cuvettes using the same dilution as that of $\mathrm{UV}-\mathrm{Vis}$ spectroscopy.

Particle size and $\zeta$-potential were measured from the diluted dispersions (absorbance $\sim 0.4$ at $850 \mathrm{~nm}$ ) in a Malvern Nano ZS instrument, according to the principles of dynamic light scattering (DLS) and electrophoresis, respectively. The device measures the particle size distribution through the DLS approach by irradiating with a $\mathrm{He}-\mathrm{Ne}$ laser at $633 \mathrm{~nm}$ and applying the Stokes - Einstein equation while assuming a single and constant diffusion rate (i.e., spherical particles). The $\zeta$-potential values were calculated from the electrophoretic mobility using Henry's equation. For the DLS measurements, a refractive index of 2.42 (carbon) was taken for SWCNT hybrids. Measurements were carried out in disposable polystyrene dip cells (code DTS1061). All $\zeta$-potential measurements were performed at least in triplicates and are referred to an average $\mathrm{pH}$ of 5.2 and a room temperature of $25^{\circ} \mathrm{C}$.

XRD patterns were collected with a Bruker D8 Advance diffractometer using a $\mathrm{Cu}$ tube as the $\mathrm{X}$-ray source $\left(\lambda_{\mathrm{CuK} \alpha}=1.54 \AA\right)$, a tube voltage of $40 \mathrm{kV}$, and a current of $40 \mathrm{~mA}$. The results were recorded in Bragg - Brentano geometry in the range of $2 \theta=\left[5-40^{\circ}\right]$, with steps of $0.05^{\circ}$ and $3 \mathrm{~s}$ accumulation time. Samples were measured in the form of spongy freeze-dried solids from the corresponding aqueous dispersions of $\mathrm{CNC} / \mathrm{SW}$ hybrids and analyzed with the fitting software Topas 5.0.

The textural characterization of $\mathrm{CNC} / \mathrm{SW}$ freezedried hybrids was carried out by $\mathrm{N}_{2}$ physisorption at $77 \mathrm{~K}$ in a Micromeritics ASAP2020 device. The specific surface area $\left(S_{\mathrm{BET}}\right)$ was calculated by applying the Brunauer-Emmett-Teller (BET) method from the data obtained from the isotherms. The total pore volume $\left(V_{\mathrm{T}}\right)$ was obtained from the adsorbed $\mathrm{N}_{2}$ amount at a relative pressure of $P / P_{0}=0.98$.

Scanning electron microscopy (SEM) was undertaken to characterize the CNC/SW morphology, by use of a JSMIT500 (Jeol, Japan), under an accelerating voltage of $25 \mathrm{kV}$. Images were taken in the secondary electron mode.

Potentiostat Autolab PGSTAT204 (Metrohm-Autolab, Utrecht, The Netherlands) was used for all electrochemical and impedance measurements. This instrument was controlled by the software Nova 1.10 .

SPCEs (DRP-110, DropSens, Oviedo, Spain) were employed. They consist of carbon working electrode $(4 \mathrm{~mm}$ diameter), carbon counter electrode, and silver reference electrode. This kind of SPCEs works as an electrochemical cell, which needs a minimum volume of $50 \mu \mathrm{L}$. 


\section{Procedures}

\section{Synthesis of CNC/SW type I and II}

Synthesis of both NC types I and II was performed according to the process described by a preceding work in our laboratories, reported elsewhere [6] (see also Supplementary Information (SI)).

For the preparation of $\mathrm{CNC} / \mathrm{SW}$ hybrids [6], in a typical experiment, $20 \mathrm{mg}$ of SWCNTs was added to $20 \mathrm{~mL}$ of the CNC aqueous colloid ( $\left.2.5 \mathrm{mg} \mathrm{mL}^{-1}\right)$, either type I or II, and sonicated using a sonic tip (Hielscher DRH-P400S; $400 \mathrm{~W}$ maximum power; $24 \mathrm{kHz}$ maximum frequency at $60 \%$ amplitude, and 50\% cycle time) for $1 \mathrm{~h}$ while cooling with an external ice bath. The obtained dispersions were then centrifuged at $1842 \mathrm{rcf}$ for $4 \mathrm{~min}$ in Falcon tubes $(20 \mathrm{~mL})$. The supernatant liquids were collected, and the sediment pellets were discarded.

Aliquots of both hybrid aqueous dispersions were freezedried to determine the SWCNT content in the sample, taking as a reference the SWCNT concentration value previously determined from UV-Vis-NIR spectroscopic measurements [25]. The absorbance value was taken at $850 \mathrm{~nm}$ to avoid influences from the background absorption, and possible changes in the intensity of SWCNT absorption bands [25]. The absorption coefficient $\left(\varepsilon_{850}=27.0 \mathrm{~mL} \mathrm{~cm}^{-1} \mathrm{mg}^{-1}\right)$ was calculated applying the Lambert-Beer law: $A_{\lambda}=\varepsilon \cdot l \cdot \mathrm{c}$, where $A_{\lambda}$ is the absorbance at a specific wavelength excitation ( $850 \mathrm{~nm}$ in this case), $l$ is the optical pathway given by the cuvette length, and $c$ is the concentration of SWCNTs expressed on $\mathrm{mg} \mathrm{mL}^{-1}$. The CNC-I/SW and CNC-II/ SW dispersions had a SWCNT concentration of 0.75 and $0.74 \mathrm{mg} \mathrm{mL}^{-1}$, respectively.

\section{Electrode fabrication}

A control SWCNT suspension was prepared adding $13 \mathrm{mg}$ of as-received SWCNT in $50 \mathrm{~mL}$ of DMF. Then, this suspension was sonicated for $1 \mathrm{~h}$ using an ultrasound bath $(3,000,683$, P. Selecta, Barcelona, Spain) and an ultrasound probe (VCX130, Sonics, Newtown, USA) for $15 \mathrm{~min}$.

Stock aqueous dispersions of CNC-I/SW and CNC-II/SW were adequately diluted to obtain a final SWCNT concentration of $0.26 \mathrm{mg} \mathrm{mL}^{-1}$ for electrode preparation.

Three kinds of electrodes were built: one modified with as-received SWCNT (SWCNT-SPE), another modified with CNC-I/SW, and, finally, another modified with CNC-II/SW. Drop casting technique was used for the fabrication of all electrodes. A total of $10 \mu \mathrm{L}$ of CNC-I/SW and CNC-II/SW aqueous dispersions and SWCNT suspension $\left(0.26 \mathrm{mg} \mathrm{mL}^{-1}\right.$ SWCNT material concentration) were dropped on the surface of the ceramic slab corresponding to the former working electrode of SPCE (carbon working electrode was previously removed with a scalpel) and allowed them to dry at room temperature. Then, silver paint was used as electrical contact with the working electrode. Finally, this electric contact was isolated by using nail polish. This methodology assures us that electrochemical transduction is exclusively due to the SWCNTs.

\section{Electrochemical measurements}

Each type of electrode was characterized by electrochemical impedance spectroscopy (EIS) (frequencies from 100,000 to $0.01 \mathrm{~Hz}$ ) and by cyclic voltammetry (CV) (scan rate $100 \mathrm{mV} \mathrm{s}^{-1}$ ) using $5 \mathrm{mM} \mathrm{K}_{4} \mathrm{Fe}(\mathrm{CN})_{6} / \mathrm{K}_{3} \mathrm{Fe}(\mathrm{CN})_{6}$ in $0.1 \mathrm{M}$ $\mathrm{KCl}$ electrolyte as redox probe.

The analytes were detected by DPV with a pulse amplitude of $70 \mathrm{mV}$ and at a scan rate of $26 \mathrm{mV} \mathrm{s}^{-1}$ (anodic sweeping). All measurements were performed using phosphate buffer saline (PBS) at $\mathrm{pH} 7.4$, except measurements of AGP that were performed using phosphate buffer (PB) at $\mathrm{pH}$ 7.0.

AGP was labeled with the electrochemical tag Os(VI) $\mathrm{O}_{2}(\mathrm{OH})_{2}$ TEMED complex (AGP-Os(VI) adduct), following the previously reported protocol $[26,27]$.

For the analysis of serum samples, AGP contained in the sample was firstly labeled with the electrochemical tag according to the aforementioned protocol. Briefly, 200.5 $\mu \mathrm{L}$ of serum sample was mixed with $49.5 \mu \mathrm{L}$ of $\mathrm{Os}(\mathrm{VI})$ $\mathrm{O}_{2}(\mathrm{OH})_{2}$ TEMED solution and it was shaken for $16 \mathrm{~h}$ at $37^{\circ} \mathrm{C}$ and $950 \mathrm{rpm}$. Next, Amicon filters (cutoff $10 \mathrm{kDa}$ ) were used for removing the excess of reagent and potential interferents such as small carbohydrates labeled with $\mathrm{Os}(\mathrm{VI})$ and other small compounds present in serum. AGP$\mathrm{Os}(\mathrm{VI})$ adduct was retained in the filter. Then, this adduct was isolated from the rest of proteins by a selective acidic precipitation [28]. Briefly, $50 \mu \mathrm{L}$ of the previous solution and $100 \mu \mathrm{L}$ of $0.5 \mathrm{M}$ perchloric acid were vortex mixed in a microtube for $20 \mathrm{~s}$. Then, the acidified solution was centrifuged (Microcentrifuge MiniSpin ${ }^{\circledR}$ Eppendorf, Germany; $3000 \mathrm{~g}$ for $20 \mathrm{~min}$ ). Finally, the supernatant was neutralized by adding $0.5 \mathrm{M}$ sodium hydroxide solution, and then properly diluted in $50 \mathrm{mM} \mathrm{PB} \mathrm{pH}=7.0$ for DPV analysis.

All experiments were performed at room temperature.

\section{Results and discussion}

\section{Structural characterization of CNC/SW hybrids}

The freshly prepared $\mathrm{CNC}$ and $\mathrm{CNC} / \mathrm{SW}$ dispersions were evaluated by DLS and electrophoresis. The determined size, polydispersity index (PDI), and electrostatic stability are shown in Table 1. The size is expressed in terms of apparent radius, meaning the hydrodynamic radius. For $\mathrm{CNC}$ aqueous 
Table 1 Hydrodynamic (apparent) size, PDI, $\zeta$-potential, and NIR purity index of $\mathrm{CNC/}$ SW dispersions

\begin{tabular}{llllll}
\hline Dispersion & $\begin{array}{l}\text { Apparent } \\
\text { radius (nm) }\end{array}$ & PDI & $\zeta$-potential $(\mathrm{mV})$ & $\begin{array}{l}\text { SWCNT concentra- } \\
\text { tion }\left(\mathrm{mg} \mathrm{mL}^{-1}\right)\end{array}$ & $\begin{array}{l}\text { NIR } \\
\text { purity } \\
\text { index }\end{array}$ \\
\hline CNC-I & $115 \pm 5$ & $0.507 \pm 0.007$ & $-40.8 \pm 0.5$ & - & - \\
CNC-II & $344 \pm 8$ & $0.44 \pm 0.02$ & $-32.2 \pm 0.9$ & - & - \\
CNC-I/SW & $98 \pm 1$ & $0.265 \pm 0.006$ & $-29.4 \pm 0.3$ & 0.75 & 0.16 \\
CNC-II/SW & $231 \pm 1$ & $0.47 \pm 0.01$ & $-30.7 \pm 0.4$ & 0.74 & 0.15 \\
\hline
\end{tabular}

colloids, the apparent size of CNC type II is observed as the double of CNC type I, seemingly due to the interaction of CNC type II with a higher number of water molecules, spawned by their higher amount of surface sulfate ester groups [6], leading to an increased hydrodynamic size. For CNC/SW hybrids in water suspensions, the apparent size value is highly reduced if compared to the apparent $\mathrm{CNC}$ radius, and still higher for $\mathrm{CNC}-\mathrm{II} / \mathrm{SW}$ hybrid. The decrease of size of $\mathrm{CNC} / \mathrm{SW}$ hybrids, compared to the preceding CNC colloids, is arguably given by an effective SWCNT debundling and individualization, as previously reported [6].

Electrophoresis measurements provide the $\zeta$-potential value, directly related to the electrostatic-based stability. $\mathrm{CNC}$ and $\mathrm{CNC} / \mathrm{SW}$ hybrids in dispersion exhibited values in the range of -30 to $-45 \mathrm{mV}$, being the negative sign consistent with the $\mathrm{CNC}$ native surface charge. An aqueous dispersion may be considered stable above $20 \mathrm{mV}$ in absolute value, but this parameter would only account for the electrostatic components to the overall stabilization.

Vis-NIR absorption is one of the most accurate techniques to evaluate SWCNT purity in liquid dispersion (see further discussion in SI). Visible-NIR spectra (see SI, Fig. S1) show the peaks corresponding to electronic transitions of metallic $\left(\mathrm{M}_{11}\right)$ and semiconducting $\left(\mathrm{S}_{33}\right.$ and $\left.\mathrm{S}_{22}\right)$ SWCNTs. The observed features are consistent with SWCNTs dispersed with commercial surfactants, such as SDBS or SDS [25]. The NIR purity index (Table 1) was obtained by dividing the $S_{22}$ neat band area by the whole spectral area in the same region (850-1200 nm). We chose this specific transition for being the most prominent in this kind of SWCNTs. This ratio accounts for the carbonaceous purity of a SWCNT sample (SWCNT vs other carbon forms). In general terms, there is a visible purification effect by dispersing and centrifuging SWCNTs in CNC aqueous colloids.

Once the characterization of $\mathrm{CNC} / \mathrm{SW}$ hybrids in aqueous medium has been performed, these dispersions were freezedried as specified in the experimental section, yielding a spongy solid. According to weight measurements before and after drying, and taking the SWCNT concentration value as a reference, we estimated a SWCNT content within the dried solid of $42 \mathrm{wt} \%$ and $36 \mathrm{wt} \%$ (for CNC-I/SW and CNC-II/ $\mathrm{SW}$, respectively). These solids were characterized by XRD, to evaluate the crystalline structure of NC allomorphs in each hybrid (Fig. 1). We could not notice any crystalline feature coming from SWCNTs, mostly ascribed to the efficient debundling and individualization, coupled to the fact that the freeze-dried solids contained a much larger mass proportion of CNC. We found the four characteristic peaks of CNC type I (Fig. 1a) at $2 \theta=14.9^{\circ}, 16.6^{\circ}, 22.7^{\circ}$, and $34.6^{\circ}$, corresponding to the $(1 \overline{0}),(110),(200)$, and (004) crystalline planes, respectively. In the case of the CNC type II hybrid (Fig. 1b), the peaks observed are placed at $2 \theta=12.4^{\circ}, 20.1^{\circ}, 22.2^{\circ}$, and $34.7^{\circ}$, corresponding to the crystalline planes (150), (110), (020), and (004), respectively, and typically found in CNC type II structures. Additionally, the $\mathrm{CNC}$ type II hybrid pattern shows two minor peaks at $2 \theta=14.8^{\circ}$ and $16.7^{\circ}$ that could be related to the slight presence of type I components in the structure. However, the intensity of these peaks denotes a predominance of CNC type II. Once SWCNTs are dispersed in CNC, the resulting XRD patterns (Fig. 1c, d) highly resemble those of the original CNC dispersants. This again suggests an excellent debundling and individualization of the starting SWCNTs caused by CNC.

In addition, the specific surface area $\left(S_{\mathrm{BET}}\right)$ and the porosity of the freeze-dried hybrids were determined. From the shape of the isotherms displayed in Fig. S2, it is visible how these spongy solids have almost no trace of micropores; they are essentially meso/macroporous with similar texture. The $V_{\mathrm{T}}$ in both cases is identical $\left(0.13 \mathrm{~cm}^{3} / \mathrm{g}\right)$, meaning that the overall porosity does not depend on the CNC type. However, the $S_{\mathrm{BET}}$ differs from one hybrid to the other, being $54 \pm 8$ $\mathrm{m}^{2} / \mathrm{g}$ for CNC-I/SW and $41 \pm 6 \mathrm{~m}^{2} / \mathrm{g}$ for CNC-II/SW. This is not a significant difference, exhibiting an equivalent specific surface area, but with a distinctive feature. The steepest end of the adsorption branch of CNC-II/SW at the highest relative pressure values with respect to the CNC-I/SW hybrid points to the fact that the former would be more macroporous and the latter would be more mesoporous.

\section{Characterization and performance of $\mathrm{CNC} / \mathrm{SW}$-based electrodes}

Nanomaterial-based electrodes (CNC/SW hybrids and SWCNT) were fabricated by removing the carbon working electrode of a SPCE and then by adding the corresponding carbon nanomaterial suspension. This allows us to asseverate 
Fig. 1 XRD patterns of freezedried a CNC types I and b II, together with freeze-dried dispersions of $\mathbf{c} \mathrm{CNC}-\mathrm{I} / \mathrm{SW}$ and $\mathbf{d}$ $\mathrm{CNC}-\mathrm{II} / \mathrm{SW}$, with the associated crystalline planes of CNC type I (blue) and CNC type II (green). Asterisks denote the SWCNTs' original features
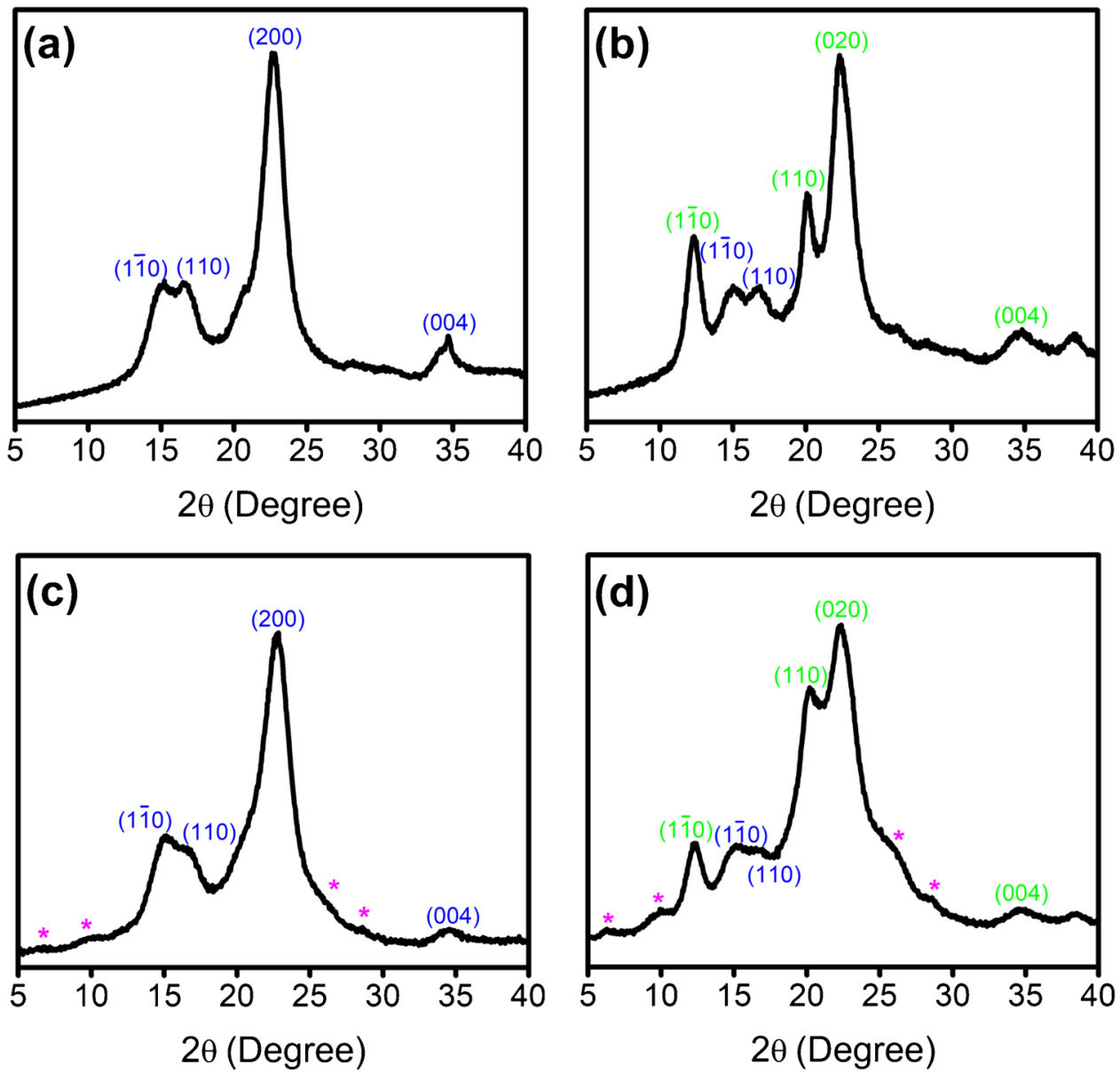

that the electrochemical behavior of these electrodes is only due to the carbon nanomaterials. The surface morphology of these electrodes was analyzed by SEM. As shown in Fig. S3, CNC/SW hybrids with a fibrillar structure are homogeneously dispersed across the whole substrate, forming an entangled network, ensuring a high contact probability with the analytes to be determined. In addition, the fibers are better defined for CNC/SW than for SWCNT modified electrodes, probably due to the lower presence of impurities.
The CNC/SW electrodes were also characterized by electrochemical techniques and compared to two controls (SPCE and SWCNT-SPE). Figure 2a shows cyclic voltammograms of $\mathrm{Fe}(\mathrm{CN})_{6}{ }^{4-} / \mathrm{Fe}(\mathrm{CN})_{6}{ }^{3-}$ (ferro/ferri system) for each material. Both $\mathrm{CNC} / \mathrm{SW}$ electrodes (blue and green lines) showed better reversibility (lesser difference between the anodic peak potential and the cathodic peak potential, as follows: $-177 \mathrm{mV}(\mathrm{CNC}-\mathrm{I} / \mathrm{SW}) \leq-184 \mathrm{mV}$ (CNC-II/ $\mathrm{SW})<-383 \mathrm{mV}(\mathrm{SPCE})<-791 \mathrm{mV}($ SWCNT-SPE$)$,
Fig. 2 a CV of SPCE (black line), SWCNT-SPE (red line), CNC-I/SW (blue line), and CNC-II/SW (green line) of $5 \mathrm{mM} \mathrm{Fe}(\mathrm{CN})_{6}^{4-} / \mathrm{Fe}(\mathrm{CN})_{6}{ }^{3-}$ in $0.1 \mathrm{M} \mathrm{KCl}$. Scan rate $0.1 \mathrm{~V} \mathrm{~s}^{-1}$. b Nyquist plots corresponding to SPCE (black line), SWCNTSPE (red line), CNC-I/SW (blue line), and CNC-II/SW (green line). Frequencies ranged from 100,000 to $0.01 \mathrm{~Hz}$ using $5 \mathrm{mM}$ $\mathrm{Fe}(\mathrm{CN})_{6}{ }^{4-} / \mathrm{Fe}(\mathrm{CN})_{6}{ }^{3-}$ in $0.1 \mathrm{M}$ $\mathrm{KCl}$ electrolyte as redox probe
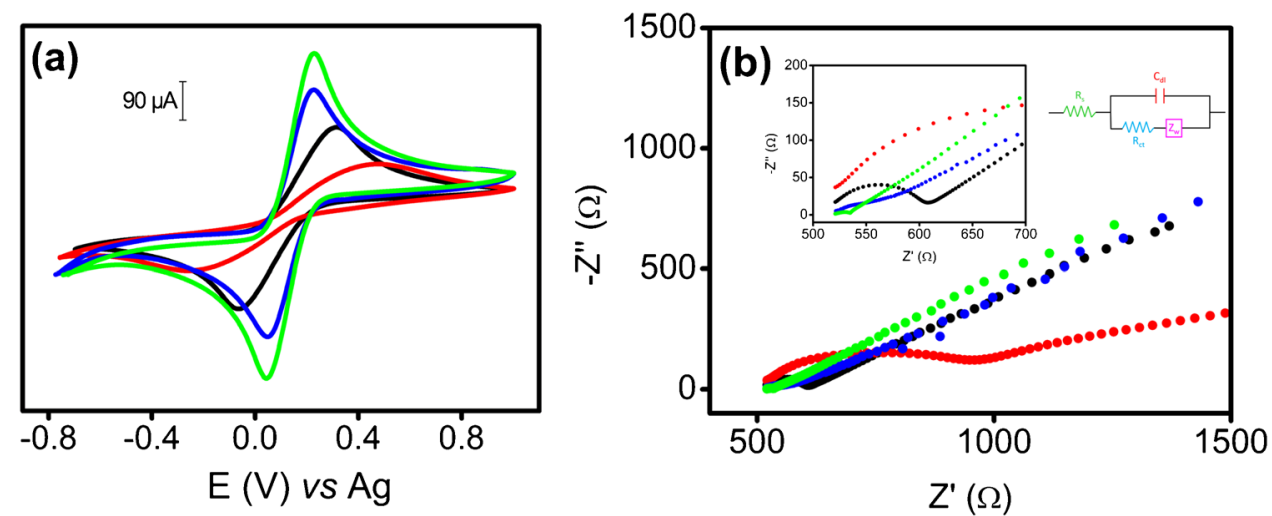
which means faster electron transfer, and highest peak currents with respect to other materials. In addition, all electrodes were analyzed by EIS. Figure $2 b$ shows the EIS results for SWCNT-SPE, SPCE, and CNC/SWs using ferro/ ferri system. Based on Nyquist plots (Fig. 2b), our samples can be sorted according to the heterogeneous charge transfer resistance as follows: SWCNT-SPE $>$ SPCE $>$ CNC-I/ $\mathrm{SW} \geq \mathrm{CNC}-\mathrm{II} / \mathrm{SW}$. Based on both studies, clearly $\mathrm{CNC} / \mathrm{SWs}$ showed the best electrochemical behavior. It is indeed striking, because $\mathrm{NC}$ is not conductive, and thus would suggest that the electrochemical reaction only happens on SWCNTs. We hypothesized that, during the synthesis of $\mathrm{CNC} / \mathrm{SW}$ hybrids, SWCNTs experienced an additional purification process, by action of SWCNT adsorption on CNC, entailing the removal of carbonaceous impurities, by selective adsorption of $\mathrm{CNC}$ onto the CNT surface, thereby isolating them aided by the centrifugation step.

This would explain, at least in part, the improvement of the electrochemical performance of the hybrids in comparison with bare SWCNT (used as control). This improvement of the electrochemical performance of SWCNTs due to the purification process agrees with previous literature [29].

Furthermore, the higher peak currents obtained by using $\mathrm{CNC} / \mathrm{SW}$ electrodes with respect to those obtained by SWCNT-SPE may be due to the higher active surface of the former.

To confirm our hypotheses, the active surface of every electrode was electrochemically measured by CV using the Randles-Sevcik equation (see SI). The surface areas of SPCE, SWCNT-SPE, CNC-I/SW, and CNC-II/SW were $0.148 \pm 0.004 \mathrm{~cm}^{2}, 0.127 \pm 0.004 \mathrm{~cm}^{2}, 0.163 \pm 0.005$ $\mathrm{cm}^{2}$, and $0.177 \pm 0.009 \mathrm{~cm}^{2}$, respectively. The CNC/SW hybrid-based electrode showed the highest active surface, increasing it by $20 \%$ in respect to SPCE. Moreover, this difference is even higher with respect to SWCNT-SPE (40\%). This means that $\mathrm{CNC} / \mathrm{SW}$ dispersions generate films with more accessible points for the electrochemical probe than bare SWCNT dispersions.

Regarding heterogeneous charge transfer and electrochemical active surface, CNC/SW hybrids offered the best analytical capabilities. Then, the analytical performance of these electrodes was evaluated by detecting several analytes with a wide variety of chemical structures and interest in the clinical field.

\section{Evaluation of detection capabilities of CNC/SW as electrochemical transducers}

Target metabolites were selected for this study: dopamine (DP), uric acid (UA), and tyrosine (Tyr). All of them are involved in fundamental biological processes and their monitoring is interesting in the clinical field [30-32]. Specifically, the simultaneous detection of these compounds was carried out by DPV. As displayed in Fig. 3, CNC/SW-based electrodes yielded better electrochemical behavior in terms of sensitivity (peak intensity) and selectivity (peak resolution) than the controls (SWCNT-SPE and SPCE). On the other hand, RSD values of analyte peak heights using different electrodes $(n=3)$ were $\leq 8 \%$ for SPCE, $\leq 6 \%$ for $\mathrm{CNC}-\mathrm{I} /$ $\mathrm{SW}$, and $\leq 9 \%$ for $\mathrm{CNC}-\mathrm{II} / \mathrm{SW}$.

Then, the calibration of each metabolite for the electrochemical transducers assayed (except SWCNT-SPE) was carried out. The analytical characteristics of calibration graphs are shown in the SI (Table S1). While the use of $\mathrm{CNC} / \mathrm{SW}$ electrodes improves the method sensitivity (calibration slopes) in comparison to SPCE for all analytes studied (around one order of magnitude), similar LODs were obtained in all cases studied.

After studying these metabolites, we explored the potential of $\mathrm{CNC} / \mathrm{SW}$ hybrids for the quantification of glycoproteins, which are biomacromolecules with high clinical relevance because some of them are used as disease biomarkers. AGP, which is an inflammatory disease biomarker [26, 33], was selected for this purpose. It was labeled with the electrochemical tag Os(VI) $\mathrm{O}_{2}(\mathrm{OH})_{2}$ TEMED (AGP-Os(VI) adduct) $[26,27]$, and then measured by DPV. Figure 4 shows the voltammograms for AGP using the aforementioned electrodes. While the use of SPCE provided a small and broad peak at $-1.3 \mathrm{~V}, \mathrm{CNC} /$ SWs produced an intense and well-defined peak at $-1.0 \mathrm{~V}$. More interestingly, CNC-II/SW yielded a peak higher than CNC-I/SW. Furthermore, no signal was recorded using SWCNT-SPE. In addition, the repeatability was good with

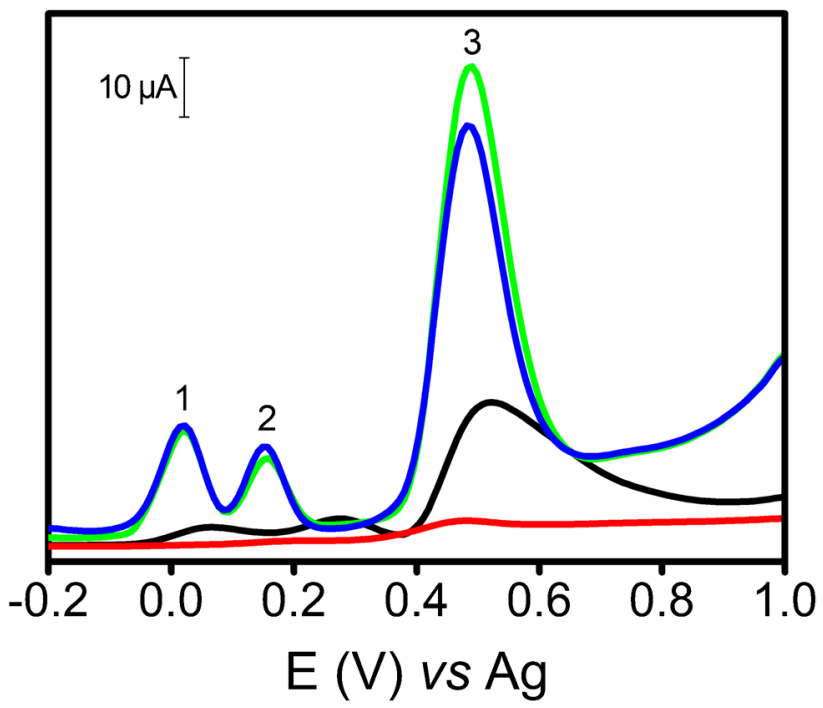

Fig. 3 DPVs of DP $0.05 \mathrm{mM}$ (peak 1), UA $0.1 \mathrm{mM}$ (peak 2), and Tyr $1 \mathrm{mM}$ (peak 3), using SPCE (black line), SWCNT-SPE (red line), $\mathrm{CNC}-\mathrm{I} / \mathrm{SW}$ (blue line), and CNC-II/SW (green line). Experimental conditions: $0.01 \mathrm{M}$ PBS ( $\mathrm{pH}=7.4$ ), pulse amplitude $70 \mathrm{mV}$, and scan rate $26 \mathrm{mV} \mathrm{s}^{-1}$ 


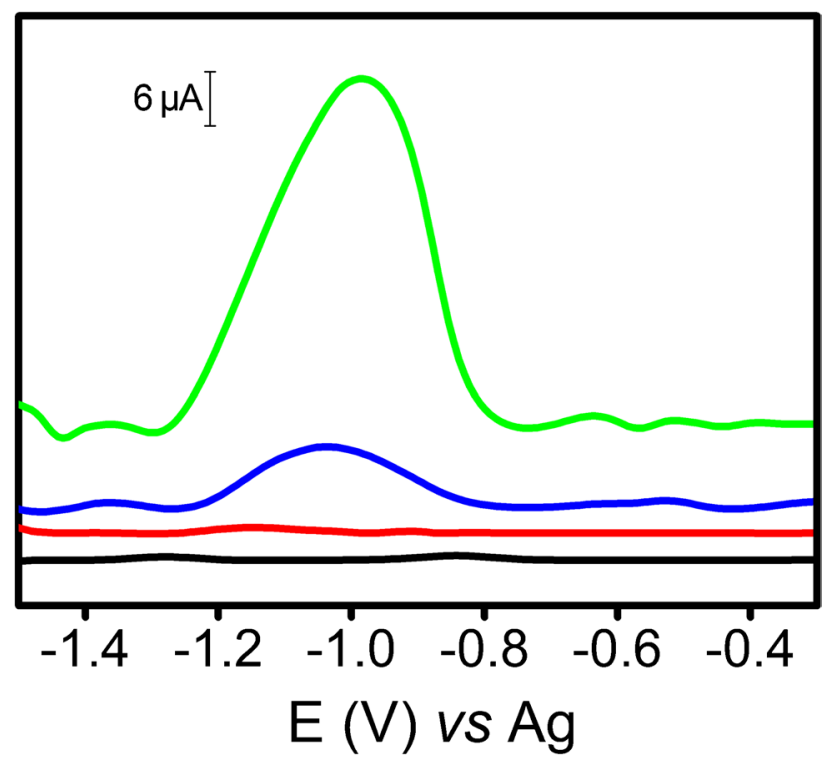

Fig. 4 DPVs of $60 \mathrm{mg} \mathrm{L}^{-1}$ AGP-Os (VI) adduct using SPCE (black line), SWCNT-SPE (red line), CNC-I/SW (blue line), and CNC-II/ SW (green line). Experimental conditions: $50 \mathrm{mM}$ phosphate buffer $(\mathrm{pH}=7.0)$, pulse amplitude $70 \mathrm{mV}$, and scan rate $26 \mathrm{mV} \mathrm{s}^{-1}$. Voltammograms were linearized

RSD values for AGP peak height of 3\%, 10\%, and 5\% for SPCE, CNC-I/SW, and CNC-II/SW, respectively $(n=3)$.

Therefore, the type of CNC resulted critical for the sensor performance in the determination of this glycoprotein of high relevance. This fact may be related to the differences in porosity. As it was, CNC-II/SW is more macroporous and $\mathrm{CNC}-\mathrm{I} / \mathrm{SW}$ is more mesoporous. This could explain why CNC-II/SW exhibits higher signal for macromolecules than $\mathrm{CNC}-\mathrm{I} / \mathrm{SW}$, likely due to the higher amount and accessibility of its macropores for this kind of analytes [34]. Nevertheless, it is worth noting that the porosity was evaluated using freeze-drying hybrids and the electrochemical sensor operates in aqueous media, so this comparison should be taken only as indicative.

Another glycoprotein of high significance used as disease biomarker, transferrin [35], was analyzed using the same methodology (see Fig. S4). Interestingly, the same results for each kind of electrode were observed, wherein CNC-II/SW yielded the highest peak too. This finding indicates the potential significance of the cellulose polymorphism on electrochemical sensing of glycoproteins.

Due to the better electrochemical behavior of the CNCII/SW transducer on AGP detection, it was chosen to carry out its quantitative determination. The main analytical characteristics of methodological calibration are listed in Table 2. CNC-II/SW hybrids showed a linear response in the studied AGP concentration range (from 20 to $100 \mathrm{mg}$ $\mathrm{L}^{--1}$ ), showing around 20 times higher sensitivity in terms
Table 2 Analytical characteristics of calibration graphs for AGP using CNC-II/SW

\begin{tabular}{lllll}
\hline $\begin{array}{l}\text { Linear range } \\
\left(\mathrm{mg} \mathrm{L}^{-1}\right)\end{array}$ & $r$ & $a \pm s_{\mathrm{a}}(\mu \mathrm{A})$ & $\begin{array}{l}b \pm s_{\mathrm{b}}(\mu \mathrm{A} \\
\left.\mathrm{mg}^{-1} \mathrm{~L}\right)\end{array}$ & $\mathrm{LOD}\left(\mathrm{mg} \mathrm{L}^{-1}\right)$ \\
\hline $20-100$ & 0.998 & $3 \pm 1$ & $0.40 \pm 0.05$ & 7 \\
\hline
\end{tabular}

of calibration slope $(0.02 \pm 0.01)$ than $\mathrm{CNC}-\mathrm{I} / \mathrm{SW}$, with a LOD of $7 \mathrm{mg} \mathrm{L}^{-1}$ (3S/N criterion).

Finally, the CNC-II/SW-based sensor accuracy was carefully evaluated. The amount of AGP was quantified in a certified reference material (human serum) by DPV using CNC-II/SW, obtaining a value of $447 \pm 42 \mathrm{mg} \mathrm{L}^{-1}(n=3)$. The concentration of AGP in the certified reference material is $617 \mathrm{mg} \mathrm{L}^{-1}$, so the recovery was $72 \pm 7 \%(n=3)$. It is necessary to bear in mind that these recovery levels were reproducible and quantitative well-enough, since the maximum recovery level obtained for AGP using acid precipitation, necessary for its selective determination, is $80 \%$ [26, 28].

This simple sample preparation methodology is also very attractive because the use of bioreagents (antibodies, enzymes, etc.) is avoided, showing a very good selectivity for AGP determination in complex samples. In addition, the increase of AGP levels during an inflammatory process is 2 - to 3 -folds [36], so that the sensor would be able to clearly monitor these changes.

\section{Conclusions}

CNC/non-oxidized SWCNT hybrid transducers smartly exploited the excellent dispersive action of CNC towards non-oxidized SWCNTs in water (scarcely addressed), which is of relevance to preserve their conductive properties, avoiding the use of organic solvents or the incorporation of toxic surfactants during their processing, making the $\mathrm{CNC} / \mathrm{SW}$ hybrids promising nanomaterials for electrochemical detection following greener approaches.

They showed their potential applicability in clinical sensing by detecting target metabolites and glycoproteins, with an improved analytical performance in comparison with commercial electrodes or their counterparts with just nonoxidized SWCNTs.

Interestingly, the $\mathrm{CNC}$ polymorphism was critical in the electrochemical detection of AGP, in which CNC-II/SW hybrid showed greater sensitivity than $\mathrm{CNC}-\mathrm{I} / \mathrm{SW}$, probably due to its macroporous structure. However, more studies to understand the CNC polymorphism influence on electrochemical sensing of glycoproteins and other related macromolecules are highly needed.

Given the increasing interest in using greener methods to process and exploit the enormous potential of carbon 
nanostructures, this work opens new avenues in the development of electrochemical sensors for detecting a wide plethora of analytes.

Supplementary Information The online version contains supplementary material available at https://doi.org/10.1007/s00604-021-05161-w.

Acknowledgements T.S. acknowledges the FPI fellowship from the University of Alcala. S.D. acknowledges the FPI fellowship from Spanish Ministry of Economy and Competitiveness. M.A.A.-S. acknowledges his DGA fellowship. J.M.G.-D. acknowledges Spanish MINEICO for his Juan de la Cierva Incorporación research contract (ref IJCI-2016-27789).

Funding Open Access funding provided thanks to the CRUE-CSIC agreement with Springer Nature. This work has been financially supported by the TRANSNANOAVANSENS program from the Community of Madrid (P2018/NMT-4349), and the Spanish Ministry of Economy and Competitiveness (CTQ2017-86441-C2-1-R). Additional funding support was from Spanish MINEICO/MICINN under project with references ENE2016-79282-C5-1-R (AEI/FEDER/ UE), PID2019-104272RB-C51/AEI/10.13039/501100011033, and PID2020-120439RA-I00. Funding support from Gobierno de Aragón (Grupo Reconocido T03_20R) is also acknowledged.

José Miguel González and Alberto Escarpa want to thank in a very special way Professor María Teresa Martínez, retired Research Professor at CSIC, for having connected us all, and for having learned from her the value of scientific collaboration between groups with different specializations.

\section{Declarations}

Conflict of interest The authors declare no competing interests.

Open Access This article is licensed under a Creative Commons Attribution 4.0 International License, which permits use, sharing, adaptation, distribution and reproduction in any medium or format, as long as you give appropriate credit to the original author(s) and the source, provide a link to the Creative Commons licence, and indicate if changes were made. The images or other third party material in this article are included in the article's Creative Commons licence, unless indicated otherwise in a credit line to the material. If material is not included in the article's Creative Commons licence and your intended use is not permitted by statutory regulation or exceeds the permitted use, you will need to obtain permission directly from the copyright holder. To view a copy of this licence, visit http://creativecommons.org/licenses/by/4.0/.

\section{References}

1. Thomas B, Raj MC, Athira KB, Rubiyah MH, Joy J, Moores A, Drisko GL, Sanchez C (2018) Nanocellulose, a versatile green platform: from biosources to materials and their applications. Chem Rev 118:11575-11625. https://doi.org/10.1021/acs.chemr ev.7b00627

2. Tan K, Heo S, Foo M, Chew IM, Yoo C (2019) An insight into nanocellulose as soft condensed matter : challenge and future prospective toward environmental sustainability. Sci Total Environ 650:1309-1326. https://doi.org/10.1016/j.scitotenv.2018.08.402

3. Ngwabebhoh FA, Yildiz U (2019) Nature-derived fibrous nanomaterial toward biomedicine and environmental remediation: today's state and future prospects. J Appl Polym Sci 136:1-21. https://doi. org/10.1002/app.47878

4. Abitbol T, Rivkin A, Cao Y, Nevo Y, Abraham E, Ben-shalom T, Lapidot S, Shoseyov O (2016) Nanocellulose, a tiny fiber with huge applications. Curr Opin Biotechnol 39:76-88. https://doi. org/10.1016/j.copbio.2016.01.002

5. Gong J, Mo L, Li J (2018) A comparative study on the preparation and characterization of cellulose nanocrystals with various polymorphs. Carbohydr Polym 195:18-28. https://doi.org/10.1016/j. carbpol.2018.04.039

6. González-Domínguez JM, Ansón-Casaos A, Grasa L, Abenia L, Salvador A, Colom E, Mesonero JE, García-Bordejé JE, Benito AM, Maser WK (2019) Unique properties and behavior of nonmercerized type-II cellulose nanocrystals as carbon nanotube biocompatible dispersants. Biomacromol 20:3147-3160. https:// doi.org/10.1021/acs.biomac.9b00722

7. Ling Z, Zhang X, Yang G, Takabe K, Xu F (2018) Nanocrystals of cellulose allomorphs have different adsorption of cellulase and subsequent degradation. Ind Crops Prod 112:541-549. https://doi.org/10.1016/j.indcrop.2017.12.052

8. Salimi S, Sotudeh-Gharebagh R, Zarghami R, Chan SY, Yuen KH (2019) Production of nanocellulose and its applications in drug delivery: a critical review. ACS Sustain Chem Eng 7:15800-15827. https://doi.org/10.1021/acssuschemeng.9b027 44

9. Wang D (2019) A critical review of cellulose-based nanomaterials for water purification in industrial processes. Cellulose 26:687701. https://doi.org/10.1007/s10570-018-2143-2

10. Calvo V, Torrubia J, Blanco D, García-Bordeje E, Maser WK, Benito AM, González-Domínguez JM (2020) Optimizing bacterial cellulose production towards materials for water remediation. In: Petkov P, Achour M, Popov C (eds) Nanoscience and nanotechnology in security and protection against CBRN threats. NATO Science for Peace and Security Series B: Physics and Biophysics. Springer, Dordrecht, pp 391-403. https://doi.org/10.1007/ 978-94-024-2018-0 31

11. Vilela C, Moreirinha C, Domingues EM, Figueiredo FML, Almeida A, Freire CSR (2019) Antimicrobial and conductive nanocellulose-based films for active and intelligent food packaging. Nanomaterials 9:980. https://doi.org/10.3390/nano9070980

12. Souza E, Gottschalk L, Freitas-Silva O (2020) Overview of nanocellulose in food packaging. Recent Pat Food Nutr Agric 11(2):154-167. https://doi.org/10.2174/22127984106661907151 53715

13. Golmohammadi H, Morales-Narváez E, Naghdi T, Merkoçi A (2017) Nanocellulose in sensing and biosensing. Chemistry Mater 29:5426-5446. https://doi.org/10.1021/acs.chemmater.7b01170

14. Ummartyotin S, Manuspiya H (2015) A critical review on cellulose : from fundamental to an approach on sensor technology. Renew Sustain Energy Rev 41:402-412. https://doi.org/10.1016/j. rser.2014.08.050

15. Shalauddin M, Akhter S, Basirun WJ, Bagheri S, Anuar NS, Johan MR (2019) Hybrid nanocellulose/f-MWCNTs nanocomposite for the electrochemical sensing of diclofenac sodium in pharmaceutical drugs and biological fluids. Electrochim Acta 304:323-333. https://doi.org/10.1016/j.electacta.2019.03.003

16. Ortolani TS, Pereira TS, Assumpçao MHMT, Vicentini FC, Gabriel de Oliveira G, Janegitz BC (2019) Electrochemical sensing of purines guanine and adenine using single-walled carbon nanohorns and nanocellulose. Electrochim Acta 298:893-900. https://doi.org/10.1016/j.electacta.2018.12.114

17. Anirudhan TS, Deepa JR, Binussreejayan (2018) Electrochemical sensing of cholesterol by molecularly imprinted polymer of silylated graphene oxide and chemically modified nanocellulose polymer. Mater Sci Eng C 92:942-956. https://doi.org/10.1016/j. msec.2018.07.041 
18. Shahrokhian S, Naderi L, Ghalkhani M (2015) Nanocellulose / carbon nanoparticles nanocomposite film modified electrode for durable and sensitive electrochemical determination of metoclopramide. Electroanalysis 27:2637-2644. https://doi.org/10.1002/ elan.201500266

19. Shahrokhian S, Balotf H, Ghalkhani M (2015) Nano composite coating based on cellulose nanofibers / carbon nanoparticles : application to voltammetric determination of clonazepam. J Solid State Electrochem 19:251-260. https://doi.org/10.1007/ s10008-014-2597-6

20. Hajian A, Lindström SB, Pettersson T, Hamedi MM, Wågberg L (2017) Understanding the dispersive action of nanocellulose for carbon nanomaterials. Nano Lett 17:1439-1447. https://doi.org/ 10.1021/acs.nanolett.6b04405

21. Mougel JB, Adda C, Bertoncini P, Capron I, Cathala B, Chauvet $\mathrm{O}$ (2016) Highly efficient and predictable noncovalent dispersion of single- walled and multi-walled carbon nanotubes by cellulose nanocrystals. J Physical Chem 120:22694-22701. https://doi.org/ 10.1021/acs.jpcc.6b07289

22. Zimmerman JB, Anastas PT, Erythropel HC, Leitner W (2020) Designing for a green chemistry future. Science 367:397-400. https://doi.org/10.1126/science.aay3060

23. Gałuszka A, Migaszewski Z, Namieśnik J (2013) The 12 principles of green analytical chemistry and the SIGNIFICANCE mnemonic of green analytical practices. TrAC 50:78-84. https://doi. org/10.1016/j.trac.2013.04.010

24. Cho SY, Yu H, Choi J, Kang H, Park S, Jang JS, Hong HJ, Kim ID, Lee SK, Jeong HS, Jung HT (2019) Continuous meter-scale synthesis of weavable tunicate cellulose/carbon nanotube fibers for high-performance wearable sensors. ACS Nano 13:93329341. https://doi.org/10.1021/acsnano.9b03971

25. Ansón-Casaos A, González-Domínguez JM, Lafragüeta I, Carrodeguas JA, Martínez MT (2014) Optical absorption response of chemically modified single-walled carbon nanotubes upon ultracentrifugation in various dispersants. Carbon N Y 66:105-118. https://doi.org/10.1016/j.carbon.2013.08.048

26. Sierra T, González MC, Moreno B, Crevillen AG, Escarpa A (2018) Total $\alpha 1$-acid glycoprotein determination in serum samples using disposable screen-printed electrodes and osmium (VI) as electrochemical tag. Talanta 180:206-210. https://doi.org/10. 1016/j.talanta.2017.12.018

27. Trefulka M, Paleček E (2014) Direct chemical modification and voltammetric detection of glycans in glycoproteins. Electrochem commun 48:52-55. https://doi.org/10.1016/j.elecom.2014.08.011

28. Stumpe M, Miller C, Morton NS, Bell G, Watson DG (2006) High-performance liquid chromatography determination of $\alpha 1$-acid glycoprotein in small volumes of plasma from neonates. J Chromatogr B Anal Technol Biomed Life Sci 831:81-84. https:// doi.org/10.1016/j.jchromb.2005.11.039

29. Vilela D, Ansón-Casaos A, Martínez MT, González MC, Escarpa A (2012) High NIR-purity index single-walled carbon nanotubes for electrochemical sensing in microfluidic chips. Lab Chip 12:2006-2014. https://doi.org/10.1039/c2lc40099e

30. Marek K, Seibyl J, Shoulson I, Holloway R, Kieburtz K, McDermott M, Kamp C, Shinaman A, Fahn S, Lang A, Weiner W, Welsh M (2002) Dopamine transporter brain imaging to assess the effects of pramipexole vs levodopa on Parkinson disease progression. JAMA 287:1653-1661. https://doi.org/10.1001/jama.287.13.1653

31. Alderman M, Aiyer KJV (2004) Uric acid: role in cardiovascular disease and effects of losartan. Curr Med Res Opin 20:369-379. https://doi.org/10.1185/030079904125002982

32. García-Carmona L, Moreno-Guzmán M, Sierra T, González MC, Escarpa A (2018) Filtered carbon nanotubes-based electrodes for rapid sensing and monitoring of L-tyrosine in plasma and whole blood samples. Sensors Actuators, B Chem 259:762-767. https:// doi.org/10.1016/j.snb.2017.12.090

33. Ipek IÖ, Saracoglu M, Bozaykut A (2010) $\alpha 1$-Acid glycoprotein for the early diagnosis of neonatal sepsis. J Matern Neonatal Med 23:617-621. https://doi.org/10.3109/14767050903258720

34. Rimoldi L, Pifferi V, Meroni D, Soliveri G, Ardizzone S, Falciola L (2018) Three-dimensional mesoporous silica networks with improved diffusion and interference-abating properties for electrochemical sensing. Electrochim Acta 291:73-83. https://doi. org/10.1016/j.electacta.2018.08.131

35. Caslavska J, Schild C, Thormann W (2020) High-resolution capillary zone electrophoresis and mass spectrometry for distinction of undersialylated and hypoglycosylated transferrin glycoforms in body fluids. J Sep Sci 43:241-257. https://doi.org/10.1002/jssc. 201900857

36. Shiyan SD, Bovin NV (1997) Carbohydrate composition and immunomodulatory activity of different glycoforms of $\alpha 1$-acid glycoprotein. Glycoconj J 14:631-638. https://doi.org/10.1023/A: 1018544711767

Publisher's note Springer Nature remains neutral with regard to jurisdictional claims in published maps and institutional affiliations. 